
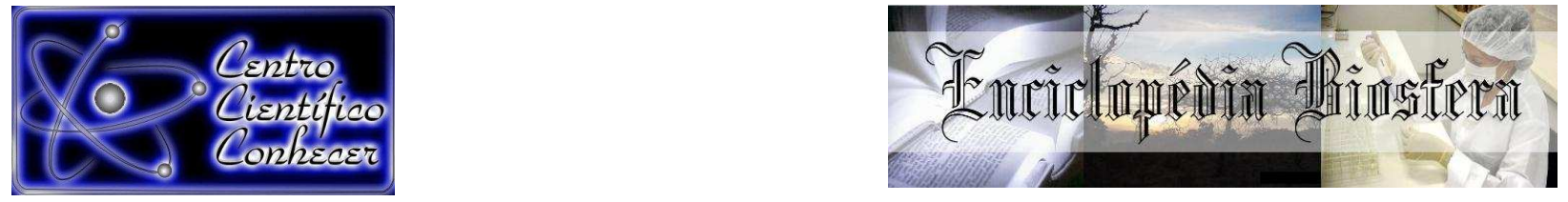

\title{
ESTIMATIVA DAS NECESSIDADES HÍDRICAS DO MILHO CULTIVADO NAS CONDIÇÕES EDAFOCLIMÁTICAS DE SÃO MATEUS - ES
}

Ramon Amaro de Sales ${ }^{1^{*}} ;$ João Marcos Louzada ${ }^{2}$; Evandro Chaves de Oliveira ${ }^{3}$; Marcus André Braido Pinheiro ${ }^{4}$; Ricardo Amaro de Sales ${ }^{5}$

$1^{*} ; 5$ Bolsista de Iniciação Científica, Engenharia Agronômica, Instituto Federal de Educação do Espírito Santo - IFES, Campus Itapina, Colatina, Brasil.

(ramonamarodesales@hotmail.com)

${ }^{4}$ Mestrando em Ciências Agrárias pela Universidade Federal São João Del Rey Campus Sete Lagoas.

${ }^{2 ; 3}$ Professor Doutor do Instituto Federal de Educação do Espírito Santo - IFES, Campus Itapina, Colatina, Brasil.

Recebido em: 08/04/2016 - Aprovado em: 30/05/2016 - Publicado em: 20/06/2016 DOI: 10.18677/Enciclopedia_Biosfera_2016_053

\section{RESUMO}

A água é um recurso que limita muito a produtividade do milho na região norte do Espírito Santo. O objetivo do trabalho foi estimar a precipitação efetiva, evapotranspiração da cultura, lâmina de irrigação e quebra de produtividade da água no cultivo do milho na região de São Mateus - ES, para diferentes épocas de semeadura. Para identificar o requerimento de água para o milho, foi utilizado o programa CROPWAT 8.0, que calcula o balanço hídrico da cultura a partir de dados climáticos, de solo e da espécie cultivada. Os resultados mostraram que o CROPWAT recomendou o uso de irrigação nas nove datas de semeadura investigadas. No entanto, a antecipação da data de semeadura para 01/09, 15/09 e 1/10, possibilitará menores lâminas de irrigação suplementar e menor quebra de produtividade de água no cultivo do milho na região.

PALAVRAS-CHAVE: Clima, solo, evapotranspiração, quebra de produtividade

\section{ESTIMATED NEEDS WATER MAIZE IN THE EDAFOCLIMATIC CONDITIONS OF SÃO MATEUS - ES}

\begin{abstract}
Water is a resource that greatly limits the productivity of maize in the northern region of the Espírito Santo. The objective was to estimate the effective precipitation, evapotranspiration, water depth and water productivity drop in corn cultivation in the region of São Mateus - ES to different sowing times. For identify the water requirement for corn was used CROPWAT 8.0 software, which calculates the water balance of culture from climatic, soil and cultivated species. The results showed that the CROPWAT recommended the use of irrigation while the nine investigated sowing dates. However, early sowing date for 01/09, 15/09 and 1/10 enable smaller blades of supplemental irrigation and break water productivity in maize cultivation in the region.
\end{abstract}

KEYWORDS: Climate, soil, evapotranspiration, yield's break 


\section{INTRODUÇÃO}

O milho é uma cultura de grande importância econômica e amplamente utilizada para alimentação de pessoas e animais em todo o mundo. No Espírito Santo, a produção de milho está muito aquém da necessidade do Estado. Conforme dados do levantamento da CONAB de abril de 2015, o Espírito Santo cultivou, na safra 2013/2014, uma área de 22,3 mil hectares de milho (Zea mays L.) com uma produção de 60,5 mil de toneladas. Por sua vez, a região de São Mateus teve um rendimento médio da produção em grãos de $1.730 \mathrm{~kg} / \mathrm{ha}$, no ano de 2013 (SIDRA, 2015).

Como todas as espécies cultivadas, o milho também está sujeito a efeitos prejudiciais decorrentes do clima, tal como o déficit hídrico, que pode afetar seu crescimento, seu desenvolvimento e sua produtividade de grãos. Segundo Landau et al., (2010) o milho, por razões essencialmente econômicas, é cultivado na maioria das áreas, na safra "das águas", ou seja, é uma cultura típica de sequeiro. A literatura tem mostrado que as maiores produtividades ocorrem quando o consumo de água durante todo o ciclo está entre 500 e $800 \mathrm{~mm}$ e que a cultura exige um mínimo de 350-500 mm para que produza sem necessidade de irrigação.

A região de São Mateus tem estação chuvosa bem definida, iniciando-se em outubro e terminando em março, quando ocorrem mais de $80 \%$ do total anual de chuvas (precipitação média anual de $1.311 \mathrm{~mm}$ ), período esse, em que se iniciam as atividades agrícolas. Contudo, apesar deste índice pluviométrico anual ser efetivo ao cultivo regular do milho, existe um risco climático que esta cultura está sujeita devido à irregularidade na distribuição de chuvas, traduzida por períodos de veranicos de diferentes durações. As perdas em produção podem variar com a intensidade e duração do estresse hídrico, sendo mais intensas quando ocorrem durante as fases mais críticas (floração e enchimento de grãos) (DOOREENBOS \& KASSAM, 1994).

As pesquisas sobre evapotranspiração fornecem informações relativas a quantidade de água consumida pelas plantas, fornecendo dados para o manejo da água e para o dimensionamento dos sistemas de irrigação (PEREIRA et al., 1997). A quantificação da evapotranspiração, mesmo em agricultura de sequeiro, é muito importante, pois, possibilita estratégias de manejo em função das condições climáticas da região e hídricas do solo. Neste sentido, a determinação da evapotranspiração de referencia (ETo) é indispensável quando na necessidade em realizar um cálculo hídrico de uma cultura, por isso em função desta necessidade surgiu um software chamado CROPWAT 8.0. Trata-se de um programa computacional criado e distribuído gratuitamente pela Organização das Nações Unidas pela Agricultura e Alimentação-FAO, (FAO 2015), desenvolvido para que se possa fazer a gestão de sistemas de irrigação e cálculos de evapotranspiração de uma cultura, podendo assim orientar épocas para plantio, estimativas de perda de produção, usando como referencia dados de clima, solo, cultivar, manejo, ciclo entre outras.

O software CROPWAT tem sido amplamente utilizado pelos pesquisadores para realizar programação de irrigação em suas pesquisas (ASHISH et. al., 2012; DORIA \& MADRAMOOTOO, 2012;). No Brasil, inúmeros pesquisadores vêm utilizando tal programa em seus trabalhos, MINUZZI \& RIBEIRO (2012), avaliaram o requerimento de irrigação do milho cultivado em Santa Catarina, durante anos do fenômeno climático La Niña. MINUZZI et al. (2013), determinaram o requerimento de água para irrigação do feijão no Rio Grande do Sul, baseado na climatologia atual e 
em cenários climáticos futuros. RODRIGUES et al. (2015), avaliaram a economia de água com base em dados atuais e históricos e comparados com os valores da lâmina obtida pelo software de referência da FAO CROPWAT 8.0.

O objetivo deste trabalho foi estimar as necessidades hídricas do milho cultivado nas condições edafoclimáticas de São Mateus - ES, para diferentes épocas de semeadura utilizando o programa CROPWAT.

\section{MATERIAL E MÉTODOS}

O estudo foi realizado no município de São Mateus, estado do Espírito Santo,

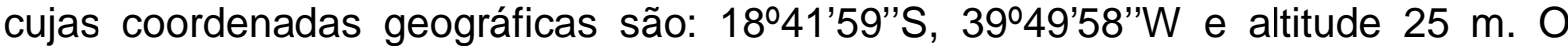
clima da região é Tropical Aw, ou seja, clima tropical úmido, com inverno seco e chuvas máximas no verão, dada pela temperatura média do mês mais frio superior a $18^{\circ} \mathrm{C}$ e a precipitação do mês mais seco inferior a $60 \mathrm{~mm}$, segundo a classificação climática de Koppen.

Foram utilizados dados meteorológicos mensais: temperatura mínima do ar (Tmin, $\left.{ }^{\complement} \mathrm{C}\right)$, temperatura máxima do ar (Tmax, $\left.{ }^{\circ} \mathrm{C}\right)$, um idade relativa do ar (UR, \%), velocidade do vento $\left(\mathrm{V}, \mathrm{m} \mathrm{s}^{-1}\right)$, precipitação pluvial (Prec, $\mathrm{mm}$ ) e insolação (n, horas), durante o período de 2002 a 2014, obtidos da estação Meteorológica do Instituto Nacional de Meteorologia - INMET, localizada no referido município, (Tabela 1).

TABELA 1. Média mensal dos dados climatológicos referentes aos anos de 2002 a 2014.

\begin{tabular}{ccccccc}
\hline Mês & Tmin $\left({ }^{\circ} \mathrm{C}\right)$ & $\operatorname{Tmax}\left({ }^{\circ} \mathrm{C}\right)$ & UR $(\%)$ & $\mathrm{V}(\mathrm{m} . \mathrm{s}-1)$ & Prec $(\mathrm{mm})$ & $\mathrm{n}$ (horas) \\
\hline Jan & 22,7 & 32,0 & 79,4 & 1,5 & 145,1 & 7,1 \\
Fev & 22,7 & 32,8 & 77,8 & 1,5 & 106,1 & 7,9 \\
Mar & 22,8 & 32,6 & 79,2 & 1,5 & 157,6 & 7,2 \\
Abri & 21,8 & 31,2 & 80,7 & 1,5 & 116,1 & 6,4 \\
Mai & 19,7 & 29,8 & 79,9 & 1,5 & 50,7 & 6.2 \\
Jun & 18,6 & 28,9 & 80,5 & 1,5 & 59,8 & 5,6 \\
Jul & 18,0 & 28,3 & 80,5 & 1,5 & 77,2 & 5,9 \\
Ago & 18,0 & 28,4 & 79,1 & 1,5 & 70,2 & 6,5 \\
Set & 18,8 & 28,8 & 76,3 & 1,5 & 55,1 & 6.1 \\
Out & 20,2 & 29,5 & 77,1 & 1,5 & 123,2 & 6,2 \\
Nov & 21,3 & 30,0 & 79,4 & 1,5 & 208,3 & 4,9 \\
Dez & 22,3 & 31,3 & 79,3 & 1,5 & 157,8 & 6,4 \\
\hline
\end{tabular}

A simulação da necessidade hídricas do milho foi realizada utilizando o programa CROPWAT-FAO versão 8.0 (Figura 1). O software pode ser obtido gratuitamente no site da FAO, no endereço eletrônico: http://www.fao.org/nr/water/infores databases cropwat.html, (FAO 2015). 


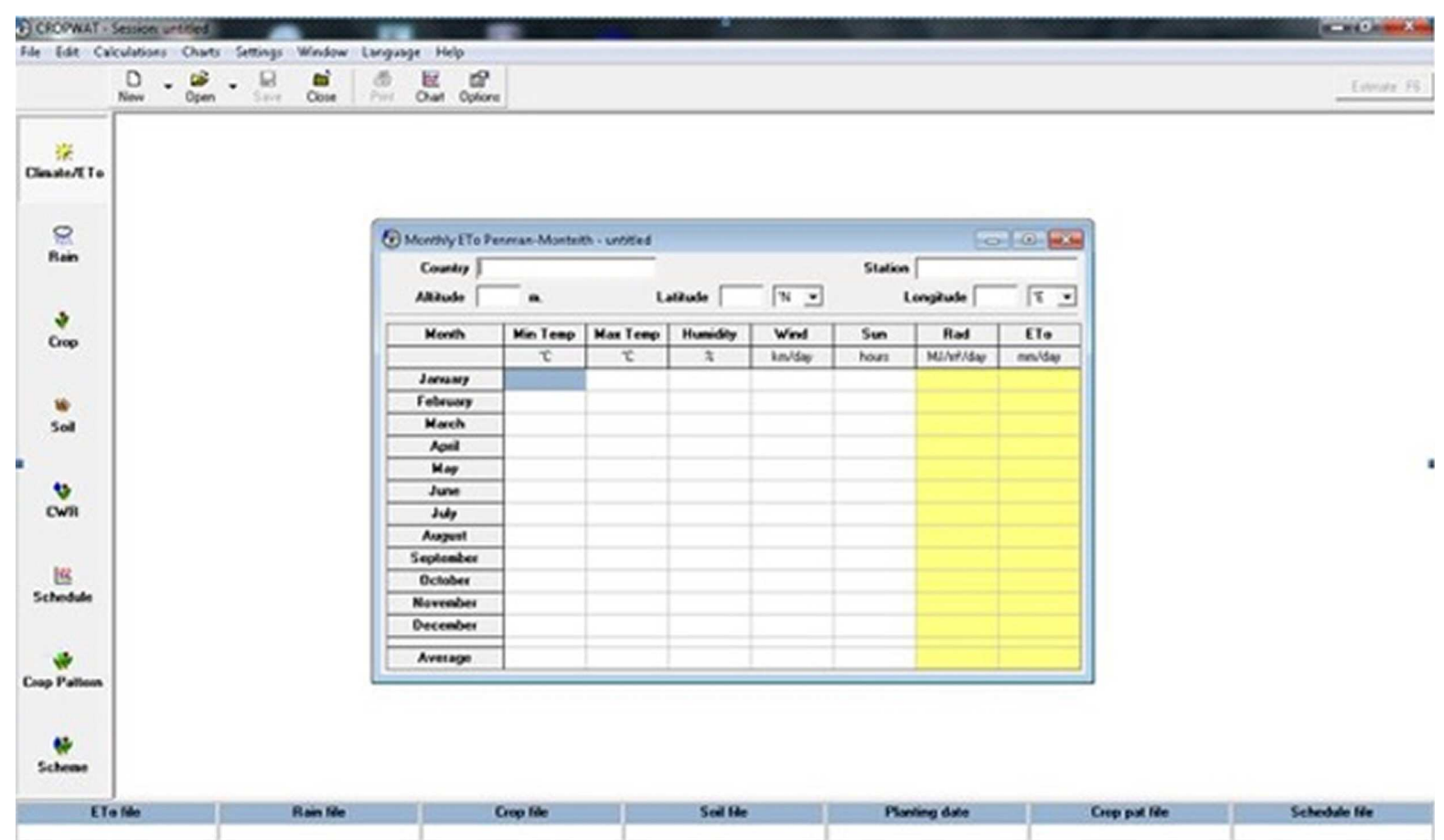

FIGURA 1. Ilustração do programa CROPWAT

A identificação dos períodos de semeadura mais adequados foi feita de acordo com as necessidades hídricas apresentadas para cada quinzena de semeadura. As datas utilizadas foram distribuídas entre os meses de setembro a dezembro para aproveitamento de água de chuva. Para tal, foram estabelecidas nove datas de semeadura para iniciar a simulação: 01/09 e 15/09 (pré-zoneamento), 1-10, 16/10, 31/10 e 15/11 (zoneamento), 1/12, 16/12 e 31/12 (pós-zoneamento), (MAPA 2016).

Para a estimativa de irrigação, foram necessários dados fenológicos da planta e do tipo do solo em estudo, adaptados de MINUZZI \& RIBEIRO (2012), (Tabelas 2 e 3). A irrigação foi realizada quando a diminuição de umidade do solo alcançar o nível onde a planta ainda pode extrair água do solo a partir do CAD (capacidade de água disponível), sem que ocorra déficit hídrico na cultura (Água Facilmente Disponível). A partir desta programação, o CROPWAT informa o valor da lâmina de água necessária quando há recomendação de irrigação, o que permite estimar o volume total de água necessário para atender o ciclo total do milho.

A quebra da produtividade do milho foi determinada em função da intensidade do déficit hídrico. Para isto, escolheu-se a opção de cálculo do balanço hídrico sem recomendação de irrigação "No irrigation (rainfed)" para aquelas semeaduras em que houve recomendação de irrigação.

Os detalhamentos dos cálculos realizados pelo CROPWAT 8.0 encontram-se em duas publicações da própria FAO (DOORENBOS \& KASSAM, 1979; ALLEN et al. 1998). 
TABELA 2. Dados fenológicos para o milho.

Fases fenológicas da cultura do milho Inicial Vegetativa Intermediária Maturação Colheita

\begin{tabular}{lccccc} 
Coeficiente de cultura (Kc) & 0.45 & & 1.2 & & 0.7 \\
Duração da fase fenológica (dias) & 20 & 30 & 65 & 15 & 130 \\
Profundidade da raiz (metro) & 0.3 & & 0.5 & & \\
Fração crítica de água no solo & 0.55 & & 0.55 & 0.77 & \\
Fator de resposta da cultura (Ky) & 0.4 & 0.5 & 0.5 & 0.2 & 1.25 \\
\hline
\end{tabular}

TABELA 3. Dados edafológicos.

Edafologia para o solo do tipo latossolo com textura média

Total de umidade disponível no solo ( $\mathrm{mm} / \mathrm{metro}$ ) 140

Taxa de infiltração máxima de chuva $(\mathrm{mm} / \mathrm{dia})$

Profundidade máxima da raiz $(\mathrm{cm})$

900

Percentual crítico de umidade do solo (\%)

A técnica de reamostragem foi utilizada por se conhecer a distribuição estatística teórica da precipitação pluvial efetiva, evapotranspiração, irrigação e quebra de produtividade no ciclo do milho. Sendo assim, gerou-se uma distribuição empírica a partir dos dados reais, tomando 1000 amostras boostrap, isto é, obtevese 1000 reamostras com reposição. Dessa forma, foi possível estimar como essa estatística amostral deveria variar devido á amostragem aleatória. Finalmente, legitimamente, a técnica de boostrap permitiu estimar a variabilidade (a dispersão da distribuição amostral empírica) existente no fenômeno em estudo e, consequentente, pôde-se construir um intervalo de confiança de $95 \%$ de probabilidade - também denominada envelope ou bandas de confiança - para as médias bootstrap das quebras de rendimento. Nota-se que, em suma, foram estimadas 1000 médias bootstrap e seus respectivos erros padrões, com os quais foi possível construir as bandas com $95 \%$ de probabilidade, considerando os percentiis $2,5 \%$ e $97,5 \%$ (EFRON, 1993). Todo o procedimento estatístico de trabalho foi executado no programa de código aberto $\mathrm{R}$ ( $R$ Core Team, 2015).

\section{RESULTADOS E DISCUSSÃO}

A Figura 2 apresenta os valores quinzenais médios de precipitação pluvial efetiva, evapotranspiração da cultura e a lâmina de irrigação necessária para atender a demanda hídrica do milho cultivado na Região de São Mateus - ES, em nove datas de semeadura na safra das águas, durante o período de 2002 a 2014. São observadas variações no acumulado de precipitação pluvial efetiva, evapotranspiração da cultura e na lâmina de irrigação para todas as datas de semeadura, os quais seguem um padrão de exigência de água para irrigação do 
milho. Deste modo, o programa CROPWAT recomendou o uso de complementação de água para terminar o ciclo do milho nas nove datas de semeadura investigadas.

As estimativas da precipitação efetiva ao longo do desenvolvimento da cultura apresentaram maiores valores nas datas de semeaduras de 01-out a 01-dez, com pico de $419 \mathrm{~mm}$ em 31-out, devido ao ciclo da cultura coincidir com o período mais chuvoso na região (Figura 2). Contudo, para a obtenção de boas produtividades a cultura do milho necessita de precipitação pluvial acima de $500 \mathrm{~mm}$ durante 0 ciclo, (MAPA 2016). Em sequencia, na Figura 2, a evapotranspiração da cultura (ETc) atingiu maior valor acumulado de $591 \mathrm{~mm}$ em 15-nov, tal fato deve-se maior disponibilidade de energia associada a maior disponibilidade de água no solo. No Rio Grande do Sul, KÖPP et al. (2015), também relacionaram a maior evapotranspiração do milho como consequências das maiores temperaturas e maior insolação quando avaliadas no município de Uruguaiana. A maior necessidade de água via irrigação foi observada em 15 de novembro, quando totalizou $251,2 \mathrm{~mm}$ de água aplicada.

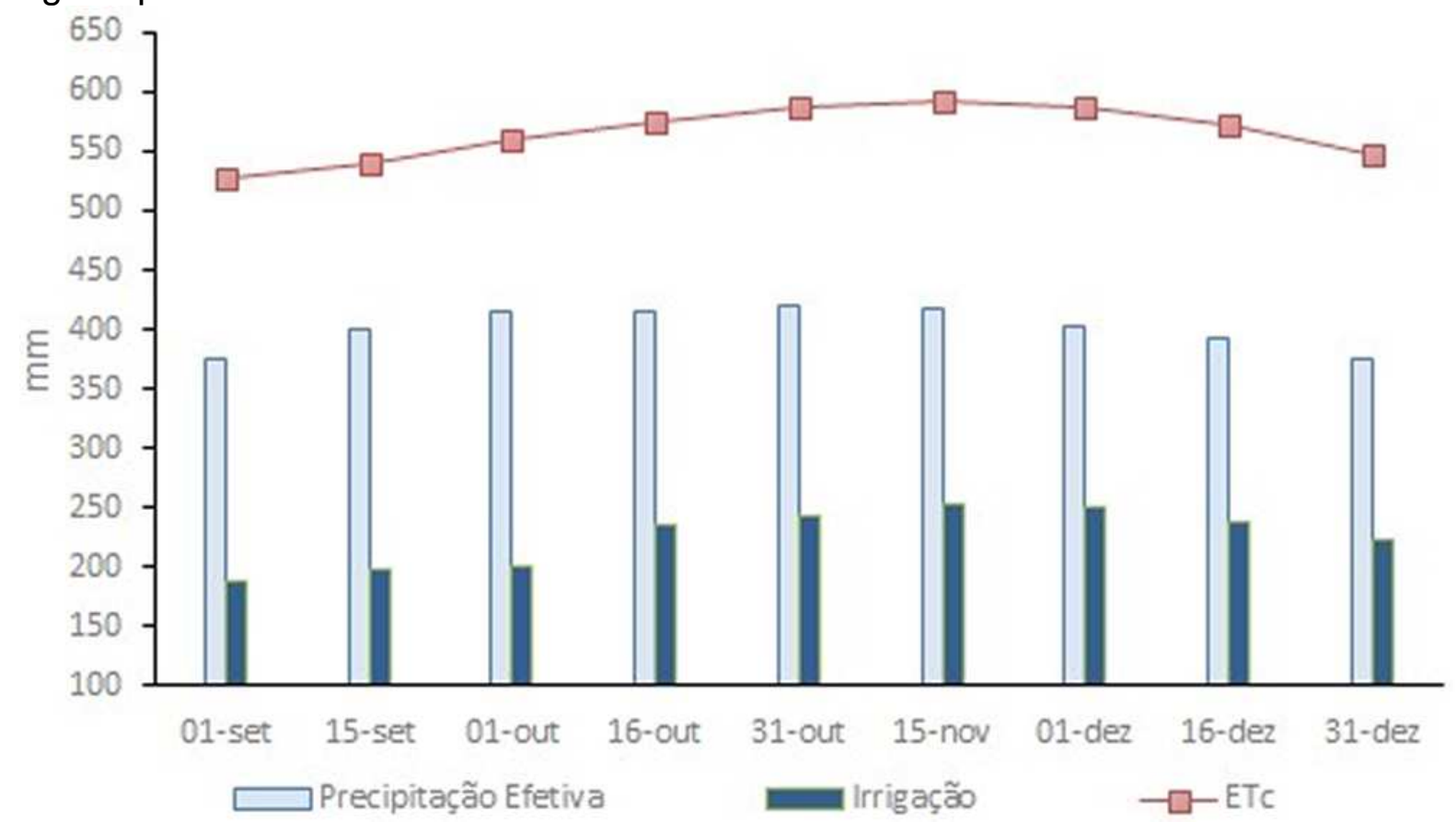

FIGURA 2. Valores médios de precipitação pluvial efetiva, evapotranspiração da cultura (ETc) e irrigação na região de São Mateus, ES no período de setembro a dezembro correspondente aos anos de 2002 a 2014.

Como observado na Figura 2, há datas de semeadura em que a cultura do milho fica exposta a baixos índices pluviométricos efetivos, que relacionada à menor evapotranspiração do milho, causa uma redução da demanda de irrigação. No entanto, conforme LANDAU et al.(2010), o milho demanda um consumo mínimo de 350-500 mm para garantir uma produção satisfatória sem necessidade de irrigação.

A menor evapotranspiração do milho correspondente a $526 \mathrm{~mm}$ (01-set) resultou em uma lâmina de irrigação suplementar de $189 \mathrm{~mm}$ (Figura 2). Por sua vez, este valor de evapotranspiração, está relacionado à demanda atmosférica e a menor disponibilidade hídrica da região. Deste modo, recomenda-se para cultivo do milho em São Mateus, a antecipação da época de semeadura até o início de outubro, como estratégia de economia de água para irrigação suplementar da cultura. SILVA et al. (2010), recomendam à antecipação ou o retardamento da ENCICLOPÉDIA BIOSFERA, Centro Científico Conhecer - Goiânia, v.13 n.23; p. 603 2016 
semeadura em relação à época de outubro e novembro, possibilitando o cultivo de outras culturas de verão em sucessão, como a safrinha do feijão, aumentando a eficiência de uso da terra e maximizando o uso do equipamento de irrigação.

$\mathrm{Na}$ Figura 3 estão ilistrados os histogramas das medições de evapotranspiração das nove datas de semeadura do milho simuladas para São Mateus-ES. Para tal, foi utilizada a distribuição empírica da evapotranspiração da cultura obtida ao completar seu ciclo por meio de reamostragem dos dados originais (13 anos), método bootstrap com 1000 repetições. Conforme pode ser observado, na data de semeadura de primeiro de setembro, $95 \%$ da evapotranspiração variou entre $506,7 \mathrm{~mm}$ a $548 \mathrm{~mm}$, e com taxa máxima de evapotranspiração de $560 \mathrm{~mm}$. A medida que ocorre $o$ atraso da semeadura, a ETc aumenta, totalizando $620 \mathrm{~mm}$ em 15 de novembro, com intervalo de confiança, variando de $572,4 \mathrm{~mm}$ a $608,6 \mathrm{~mm}$, evidenciando a variabilidade da disponibilidade hídrica nas datas de semeadura. KÖPP et al. (2015), encontraram $654 \mathrm{~mm}$ de evapotranspiração média no ciclo, com intervalo de consumo hídrico de 531 a $735 \mathrm{~mm}$.
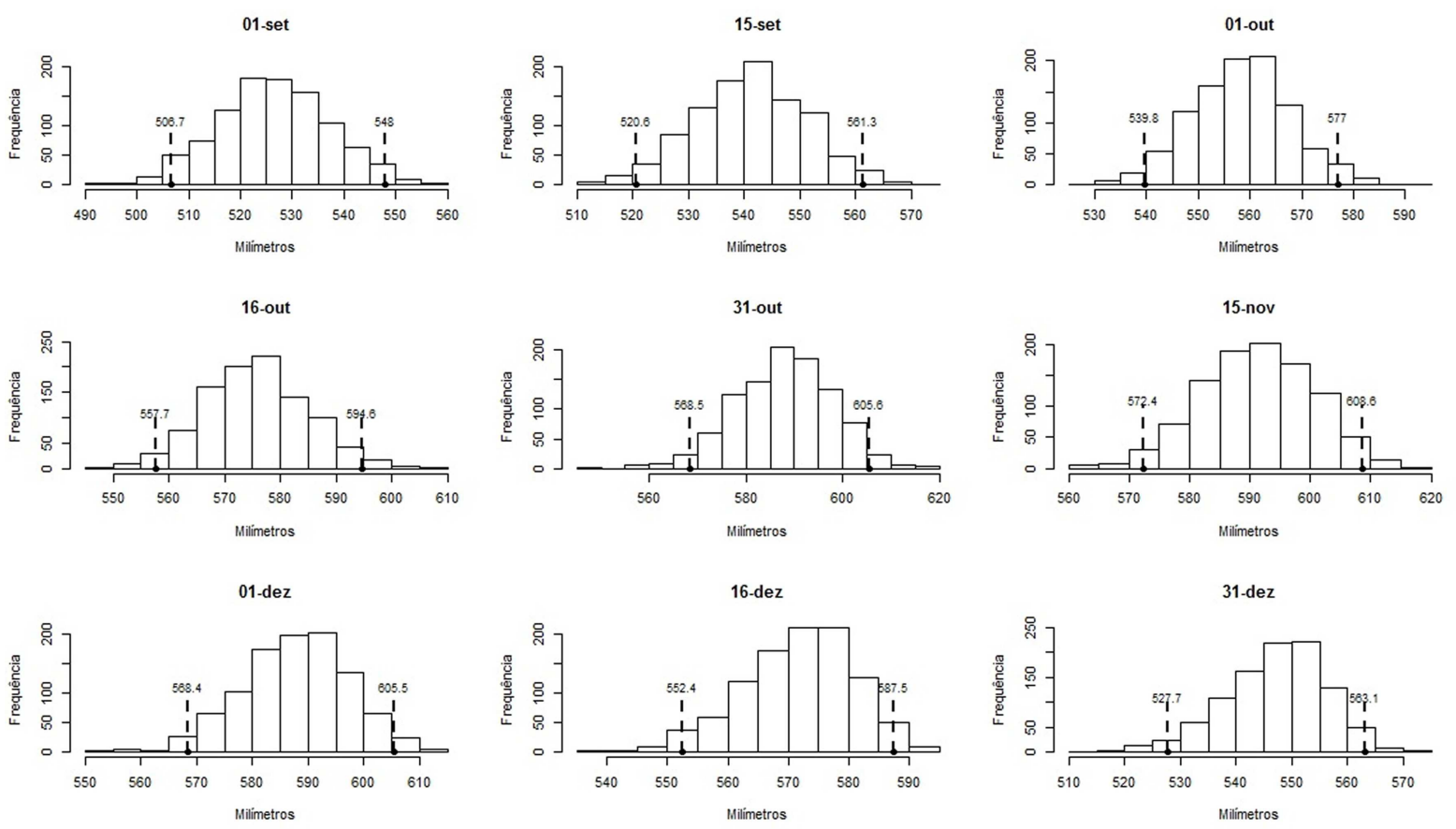

FIGURA 3. Histograma das medições de evapotranspiração para nove datas de semeadura, referentes à: 01-set, 15-set, 01-out, 16-out, 31-out, 15-nov, 01-dez, 16-dez e 31-dez. Note que as hastes verticais mostram o intervalo de confiança percentílico bootstrap para a média da ETc, com $95 \%$ de probabilidade.

Os valores de evapotranspiração do milho nas datas de semeadura de 01-set, 15-set, 01-out e 31-dez foram estatisticamente iguais, com base no intervalo percentil bootstrap (Tabela 4). 
TABELA 4. Intervalo de confiança percentil bootstrap com $97,5 \%$ de probabilidade da ETc em milímetros de todos os anos.

\begin{tabular}{cccccccccc}
\hline IC & $01 / \mathrm{set}$ & $15 / \mathrm{set}$ & $01 /$ out & $16 /$ out & $31 /$ out & $15 / \mathrm{nov}$ & $01 / \mathrm{dez}$ & $16 / \mathrm{dez}$ & $31 / \mathrm{dez}$ \\
\hline $2,5 \%$ & 503,2 & 521 & 539,9 & 558 & 568,9 & 571,8 & 567,2 & 553,1 & 527,7 \\
$97,5 \%$ & 543,3 & 556,5 & 573,5 & 591,4 & 602,3 & 606,5 & 602,4 & 586,3 & 561,4
\end{tabular}

Apresentam-se, na Tabela 5 os quartis (milímetros acumulados) a partir das 1000 repetições bootstrap, onde o quartil 100\% representa todos os valores obtidos pelo método botstrap. As maiores taxas de evapotranspiração foram de 31/out a 01/dez, com máximas acumulativas acima de $2900 \mathrm{~mm}$, indicando o potencial produtivo do milho nas referidas datas de semeadura.

TABELA 5. Quartis via bootstrap das ETc's em todas as datas de semeadura.

\begin{tabular}{cccccccccc}
\hline & 01-set & 15-set & 01-out & 16-out & 31-out & 15-nov & 01-dez & 16-dez & 31-dez \\
\hline & & & & & & & & & \\
$0 \%$ & 491,9 & 506,9 & 528,3 & 543,4 & 547,8 & 556,4 & 550,2 & 536,7 & 513,7 \\
$25 \%$ & 517,8 & 533,8 & 552,0 & 569,5 & 580,8 & 585,5 & 581,1 & 565,9 & 542,2 \\
$50 \%$ & 525,4 & 541,0 & 558,6 & 575,8 & 587,4 & 592,1 & 588,0 & 572,4 & 548,8 \\
$75 \%$ & 532,6 & 547,5 & 564,5 & 581,4 & 593,8 & 598,1 & 594,2 & 578,0 & 554,6 \\
$100 \%$ & 559,9 & 577,9 & 588,0 & 600,6 & 619,1 & 619,7 & 616,4 & 595,4 & 570,9 \\
\hline TOTAL & 2628 & 2707 & 2791 & 2871 & 2929 & 2952 & 2930 & 2848 & 2730 \\
\hline
\end{tabular}

Com os quartis da necessidade de irrigação para as datas estudadas. podese observar que, na data de 15-nov são necessárias as maiores lâminas suplementares de irrigação, $410 \mathrm{~mm}$ no quartil de $100 \%$, com acumulativo de 1250 $\mathrm{mm}$. Já as menores lâminas de irrigação suplementar, ocorreram em 01-set, com $334 \mathrm{~mm}$ no quartil 100\%, com acumulativos abaixo de $1000 \mathrm{~mm}$ (Figura 4). COSTA et al. (2015), analisando a resposta do milho à diferentes lâminas de irrigação, em Mossoró-RN, encontraram lâmina de $410 \mathrm{~mm}$ à $788 \mathrm{~mm}$. OLIVEIRA et al. (2012) comentam quanto à importância da necessidade de irrigação suplementar, mesmo em períodos em que as chuvas são mais frequentes, uma vez que há irregularidades na sua distribuição.

$\mathrm{Na}$ Figura 5 está representada a redução esperada na produtividade potencial da água para o cultivo do milho sem o uso da irrigação suplementar, para as datas estudadas. Nota-se que, a falta da irrigação gera as maiores reduções de produtividade de água com o retardamento da data de semeadura, principalmente, a partir de 16 de outubro, atingindo valores de quebra de produtividade superiores a $30 \%$. Enquanto, apresenta as menores reduções nas datas de semeadura de 0109, 15-09 e 01-10. Assim, pode-se concluir que, mesmo com a antecipação da data de semeadura, não irrigar significa quebra de produtividade, conforme as simulações realizadas pelo programa CROPWAT. MINUZZI \& RIBEIRO (2012) constaram que durante anos de La Niña, perdas na produtividade do milho decorrentes do déficit hídrico foram de até 35,1 \% em São Miguel do Oeste, Santa Catarina. 


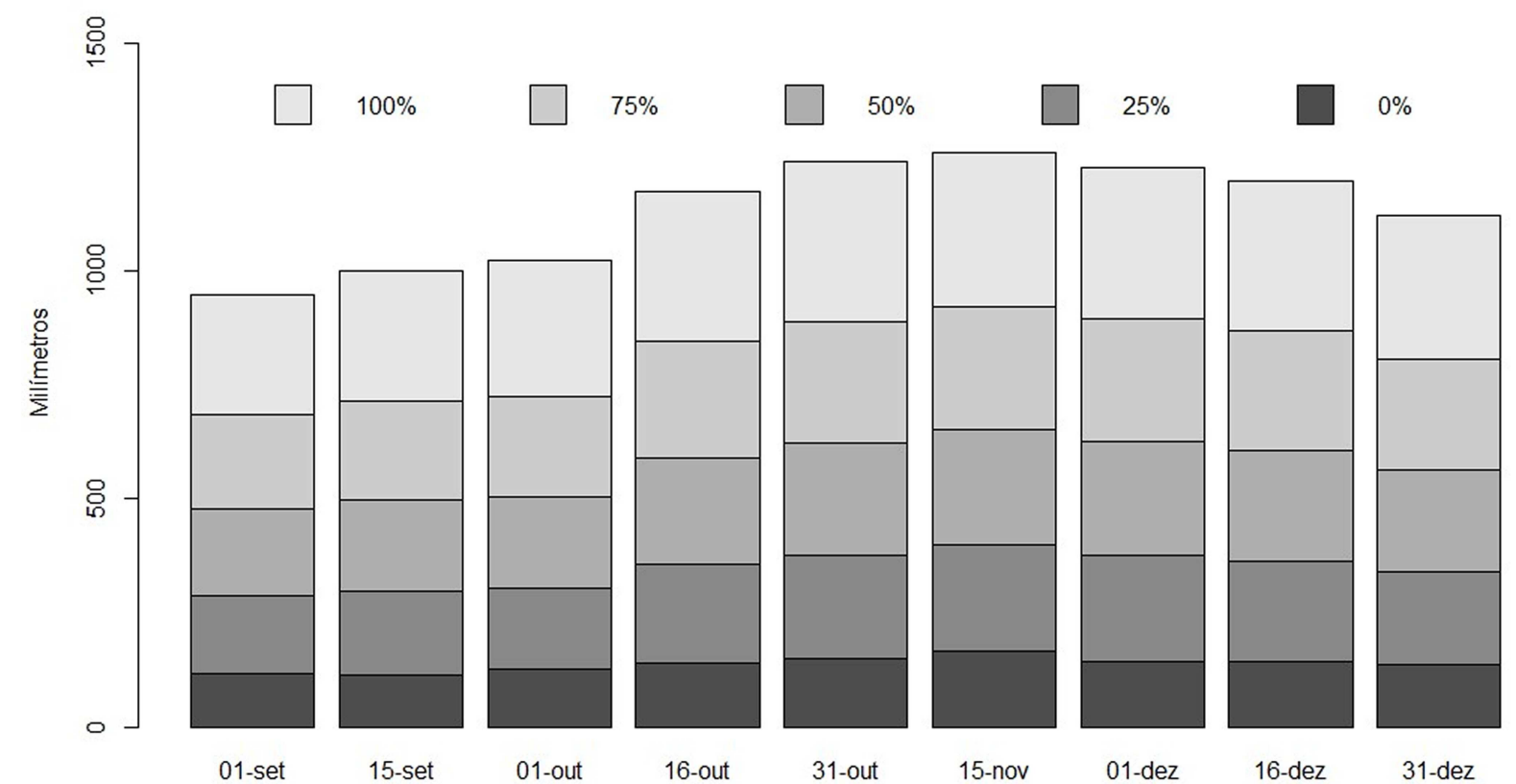

FIGURA 4. Barras apresentando os quartis (milímetros acumulados) a partir das 1000 repetições (reamostragem) bootstrap. Eixo y irrigação $(\mathrm{mm})$ eixo $\mathrm{x}$ data de semeadura.

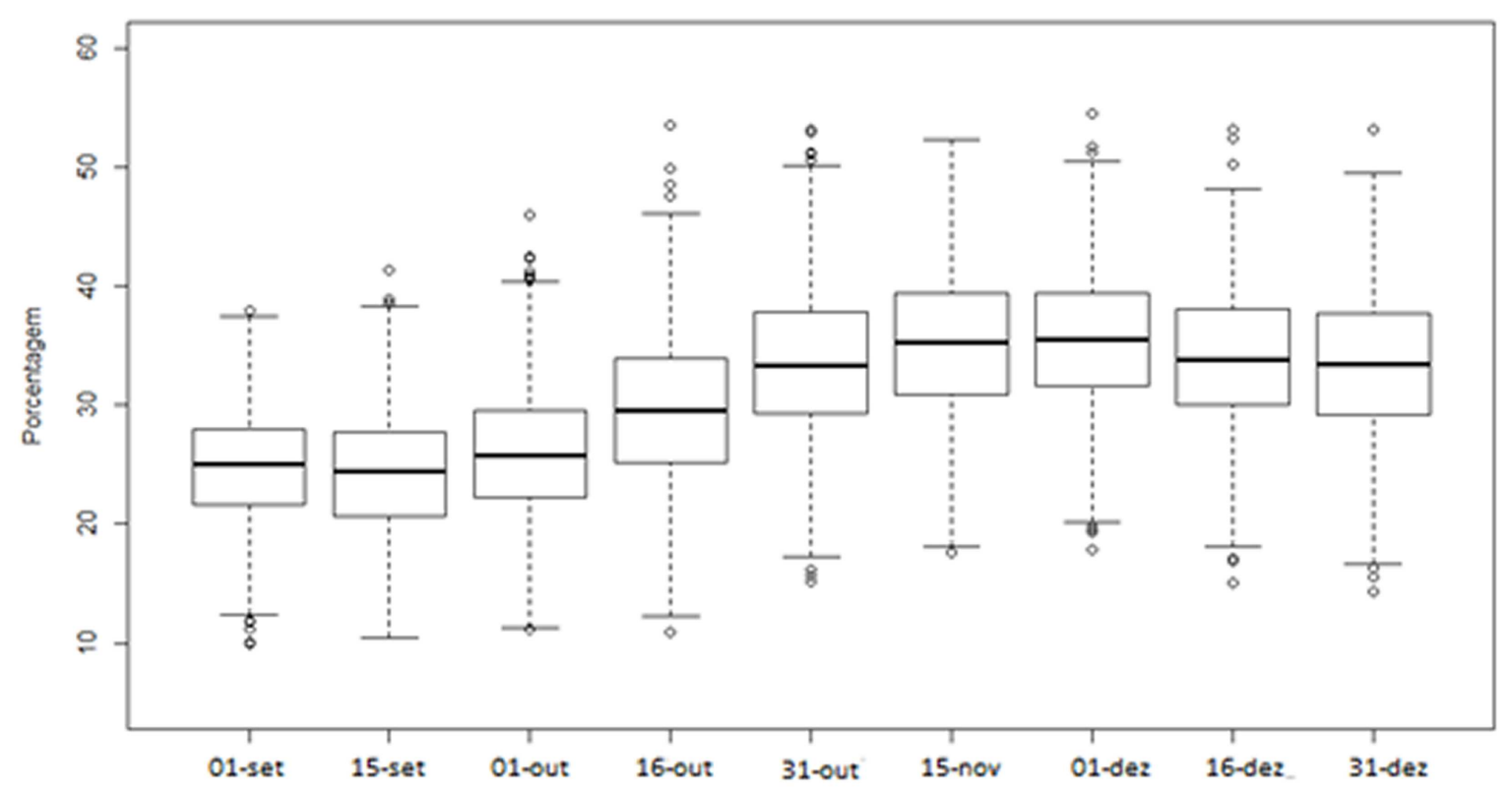

FIGURA 5. Método box-plot da distribuição de quebra de produtividade (\%) eixo y, com quartis das 1000 repetições (reamostragem) bootstrap, referentes as nove datas de plantio (eixo x) no período de 2002 a 2014.

Analisando a Tabela 6 , observa-se que resultados não se diferem estatisticamente ao nível de 2,5\%, pois há sobreposição entre os intervalos de confiança para os índices de quebra. Porém, os riscos de quebra de produtividade do milho aumentam quanto mais tardia for a semeadura, chegando a 45,9 \% no mês de dezembro. 
TABELA 6. Intervalo de confiança percentil bootstrap com $97.5 \%$ de probabilidade para a variável quebra de produtividade representada em percentagem.

\begin{tabular}{cccccccccc}
\hline IC & 01-set & 15-set & 01-out & 16-out & 31-out & 15-nov & 01-dez & 16-dez & $31-$ dez \\
\hline $2.5 \%$ & 15,1 & 14,3 & 14,9 & 18,4 & 21,0 & 23,3 & 24,1 & 21,5 & 21,0 \\
$97.5 \%$ & 33,9 & 34,5 & 36,5 & 41,8 & 45,6 & 46,6 & 46,8 & 45,1 & 45,9
\end{tabular}

Vale ressaltar novamente que, para manter as condições hídricas do solo favoráveis à absorção de água pelas plantas para a manutenção da demanda evaporativa da atmosfera na região de São Mateus-ES, a semeadura efetuada no mês de setembro e início de outubro resulta em menor consumo de água de irrigação e menor redução na produtividade durante o ciclo da cultura do milho.

\section{CONCLUSÃO}

Nas estimativas realizadas, a precipitação efetiva apresentou maiores valores nas datas de semeaduras de 01/out a 01/dez e associada à disponibilidade térmica, favoreceu a alta demanda evapotranspirométrica pela cultura do milho, resultando assim, nas maiores lâminas suplementares de irrigação.

Vale ressaltar que, o programa CROPWAT recomendou o uso de irrigação nas nove datas de semeadura investigadas. No entanto, a antecipação da data de semeadura possibilitará menores lâminas de irrigação suplementar e menor quebra de produtividade de água no cultivo do milho em São Mateus-ES.

\section{AGRADECIMENTOS}

Os autores agradecem ao IFES e à FAPES pela bolsa de estudos concedida para a realização da pesquisa e também ao e ao Instituto Nacional de Meteorologia (INMET), pela disponibilidade dos dados meteorológicos.

\section{REFERÊNCIAS}

ALLEN, R.G.; PEREIRA, L.S.; RAES, D.; SMITH, M. Crop evapotranspiration: guidelines for computing crop water requirements. Rome: FAO, 300p. (FAO. Irrigation and Drainage Paper, 56). 1998.

ASHISH, D.; MANFRED, P.; OSTROWSKI, R. P.; PANDEY, R. P. Simulation and optimization for irrigation and crop planning. Irrigation and Drainage, Malden, v. 61, n. 2, p.178-188, 2012.

CONAB. Companhia Nacional de Abastecimento. Acompanhamento da safra brasileira de grãos. V.2, n.7 (2015).

COSTA, J. P. N.; JUNIOR, E. G. C.; MEDEIROS, J. F.; GUEDES, R. A. A.; Evapotranspiração e rendimento do milho a diferentes lâminas e salinidade da água de irrigação. Irriga, Botucatu, Edição Especial, IRRIGA \& INOVAGRI, p. 74-80, 2015. 
DOORENBOS, J.; KASSAM, A.H. Yield response to water. Food and agriculture organization of the united nations - FAO, 1979. 193p.

DORIA, R. O.; MADRAMOOTOO, C. A. Retracted: Estimation of irrigation requirements for some crops in southern Quebec using CROPWAT. Irrigation and Drainage, Malden, v. 61, n. 4, p. i-xi, 2012.

EFRON, B.; TIBSHIRANI, R. J. An Introduction to the bootstrap. New York: Chapman \& Hall, 1993. 436 p.

FAO. Organização das Nações Unidas pela Agricultura e Alimentação, (2015). CROPWAT 8.0, FAO, Rome.

KÖPP, L. M.; PEITER, M. X.; BEM, L. H. B.; NOGUEIRA, H. M. C. M.; PADRÓN R. A. R.; ROBAINA, A. D.; BUSKE, T. C. Simulação da necessidade hídrica e estimativa de produtividade para cultura do milho em municípios do RS. Revista Brasileira de Milho e Sorgo. Sete Lagoas, v.14, n.2, p. 235-246, 2015.

LANDAU, E. C.; SANS, L. M. A.; D. P. SANTANA. Cultivo do milho: Clima e solo. (Sistema de Produção, 1), Embrapa Milho e Sorgo, Versão Eletrônica - 6ª edição, setembro de 2010.

MAPA - Ministério da Agricultura, Pecuária e Abastecimento. Zoneamento Agrícola de Risco Climático para a cultura de milho no Estado do Espírito Santo, anosafra 2014/2015. Disponível em http://www.agricultura.gov.br/arq editor/file/Politica Agricola/Portarias/PORT-N-148MILHO-ES. Acesso em março de janeiro de 2016.

MINUZZI, R. B.; RIBEIRO, A. J. Requerimento de água para irrigação do milho em Santa Catarina durante eventos La Niña. Revista Brasileira de Engenharia Agrícola e Ambiental (Online), Campina Grande, v. 16, p. 1330-1337, 2012.

MINUZZI, R. B.; SILVA, D. O.; PEREIRA, A. A. A. Cenários climáticos e o requerimento de água do feijão no Rio Grande do Sul. Revista Brasileira de Agropecuária Sustentável, v. 3, p. 61-73, 2013

OLIVEIRA, E. C.; COSTA, J. M. N.; PAULA JÚNIOR, T. J.; FERREIRA, W. P. M.; JUSTINO, F. B.; NEVES, L. O. The performance of the CROPGRO model for bean (Phaseolus vulgaris L.) yield simulation. Acta Scientiarum, Maringá, v.34, p.239246, 2012.

PEREIRA, A.R.; VILLA NOVA, N.A.; SEDIYAMA, G.C. Evapotranspiração. Piracicaba: FEALQ, 1997. 183p.

R Core Team. R: A language and environment for statistical computing. $R$ Foundation for Statistical Computing, Vienna, Austria, 2015. Disponível em http://www.R-project.org/. Acesso em 06 de março de 2016.

RODRIGUES, D.F.B.; ALMEIDA, C.D.G.C.; BATISTA, M.C.M. Support system for 
irrigation schedulingvia sms (short message service). Irriga, Botucatu, v. 20, n. 2, p. 286-303, 2015.

SIDRA. Sistema IBGE de Recuperação Automática. Rendimento médio da produção da lavoura temporária. Disponível em http://www.sidra.ibge.gov.br/. Acesso em 06 de março de 2016.

SILVA, P.R.F.; PIANA, A.T.; MAASS, L.B.; SERPA, M.S.; SANGOI, L.; VIEIRA, V.M.; ENDRIGO, P.C.; JANDREY, D.B. Adequação da densidade de plantas à época de semeadura em milho irrigado. Revista de Ciências Agroveterinárias, Lages, v. 9, n. 1 , p. $48-57,2010$. 